\title{
Gravity gradient tensor analysis to an active fault: a case study at the Togi-gawa Nangan fault, Noto Peninsula, central Japan
}

\author{
Yoshihiro Hiramatsu ${ }^{{ }^{*}} \mathbb{D}$, Akihiro Sawada' ${ }^{1}$ Wataru Kobayashi ${ }^{2}$, Satoshi Ishida² and Masaaki Hamada ${ }^{2}$
}

\begin{abstract}
Gravity gradient tensor analysis has been a powerful tool for investigating subsurface structures and recently its application to a two-dimensional fault structure has been developed. To elucidate the faulting type and spatial extent, specifically the continuity and the size, of the subsurface fault structure of an active fault through gravity gradient tensor analysis, we analyzed Bouguer anomalies, which were composed of dense gravity measurement data over the land and seafloor, and indices calculated from a gravity gradient tensor around the Togi-gawa Nangan fault (TNF), Noto Peninsula, central Japan. The features of Bouguer anomalies and their first horizontal and vertical derivatives demonstrate clearly that the TNF is a reverse fault dipping to the southeast. Furthermore, the combination of those derivatives and the dimensionality index revealed that the spatial extent of the subsurface fault structure is coincident with that of the surface fault trace and that it shows no evidence of connecting the TNF with surrounding active faults. Furthermore, the dip angle of the subsurface fault structure was estimated as $45^{\circ}-60^{\circ}$ from the minimum eigenvectors of the gravity gradient tensor. We confirmed that this result is coincident with the dip angle estimated using the two-dimensional Talwani's method. This high dip angle as a reverse fault suggests that the TNF has experienced inversion tectonics.
\end{abstract}

Keywords: Active fault, Bouguer anomaly, Dip angle, Two-dimensional Talwani's method, Inversion tectonics

\section{Introduction}

Elucidating the subsurface fault structure of an active fault is important for understanding regional tectonics and seismic risks. Geophysical surveys are useful for investigating subsurface structures. Fault movements displace the basement, causing gravity anomalies around an active fault. Especially, vertical displacement of the basement causes a steep change in Bouguer anomalies across the fault. Therefore, the first horizontal derivative (HD) and the first vertical derivative (VD) of Bouguer anomalies are often used to highlight subsurface fault structures. Wada et al. (2017), based on the continuity of high $\mathrm{HD}$ and the zero isoline of VD for two active fault zones on the east margin of the Niigata Plain in central Japan,

\footnotetext{
*Correspondence: yoshizo@staff.kanazawa-u.ac.jp

${ }^{1}$ School of Geosciences and Civil Engineering, College of Science and Engineering, Kanazawa University, Kakuma, Kanazawa, Ishikawa 920-1192, Japan

Full list of author information is available at the end of the article
}

inferred that subsurface fault structures are continuous. Recently, other methods to investigate the subsurface fault structure, especially for the dip angle of a fault, have been developed using the gravity gradient tensor (Kusumoto 2015, 2017). For the 2016 Kumamoto earthquake in Japan, Kusumoto (2016) used eigenvectors of the gravity gradient tensor to estimate the dip angle of the Kumamoto-Ooita tectonic line, which includes the source fault of the earthquake, as approximately $65^{\circ}$ (Beiki and Pedersen 2010). Matsumoto et al. (2016) also analyzed gravity data around the 2016 Kumamoto earthquake source fault and discussed the faulting type and segmentation of the source fault through features obtained from the gravity gradient tensor. Nevertheless, reported applications of the gravity gradient tensor to analyses of the subsurface structure of active faults are few. More case studies must be conducted to examine its effectiveness.

The study area is the western Noto Peninsula, central Japan, where dense gravity surveys have been conducted 
mainly by Kanazawa University (Honda et al. 2012) (Fig. 1). The Noto Peninsula is composed mainly of Oligocene to Early Miocene volcanic rocks and post Oligocene sediment rocks (e.g., Kaseno 1993) (Fig. 2). These volcanic rocks erupted during the rifting event of the back-arc basin of the Japanese islands. The rifting ceased during the Middle Miocene. This rifting formed normal faults around the Noto Peninsula. Some of the normal faults have been reactivated as reverse faults because of the compressive stress associated with forearc subduction (e.g., Katagawa et al. 2005).
Active Fault Research Group (1991) reported several active faults in this area, such as the Togi-gawa Nangan fault (TNF) (Figs. 1 and 2). Based on geomorphological features, Active Fault Research Group (1991) reported that the TNF is a reverse fault with uplift on the southeastern side. Imaizumi et al. (2018) extended the eastern end of the TNF through re-evaluation of geomorphological features (Figs. 1 and 2). This fault is located along the boundary between late Pleistocene to Holocene sediments/sand dune deposits and Miocene andesite on the ground surface (Fig. 2).

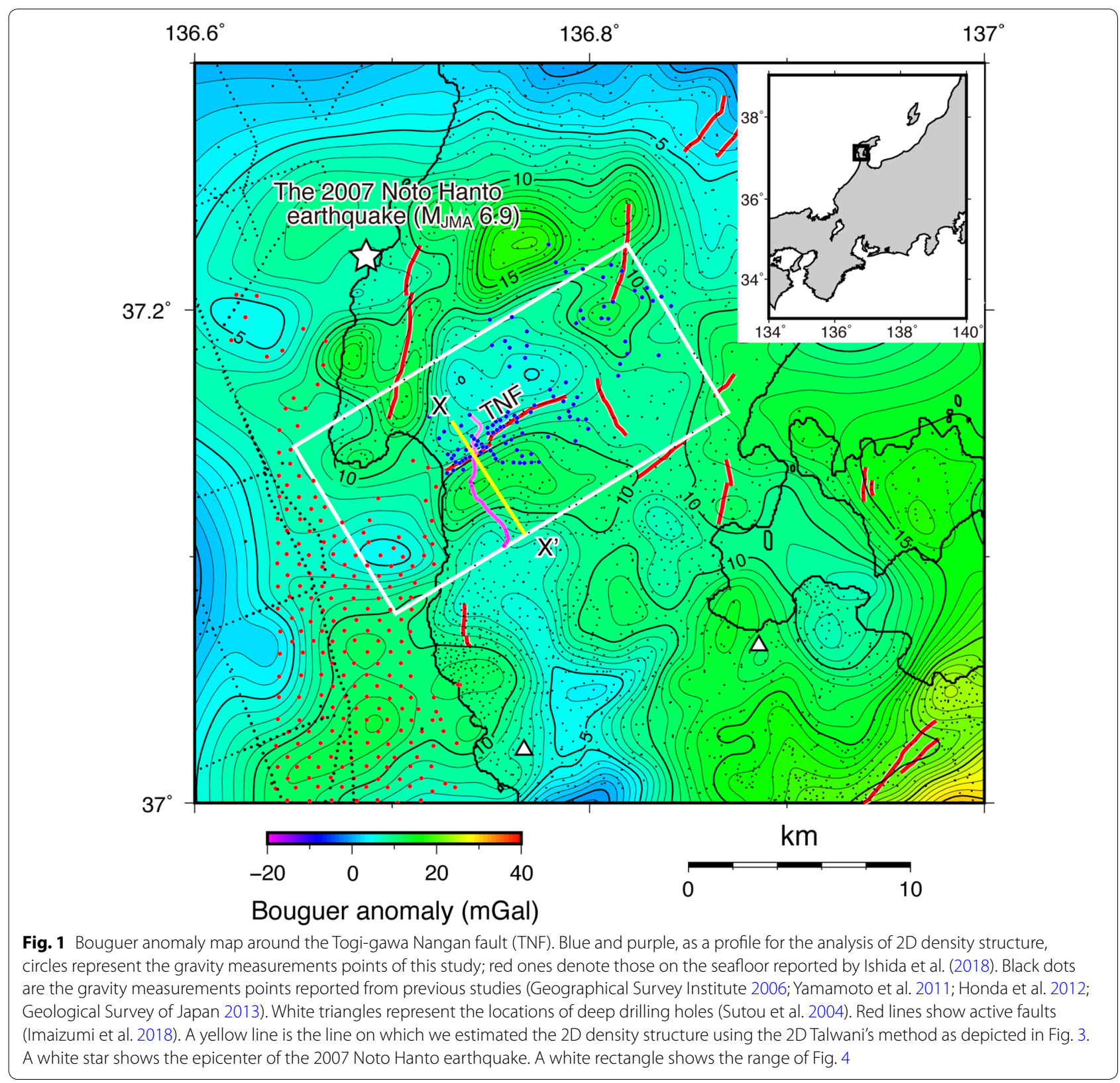




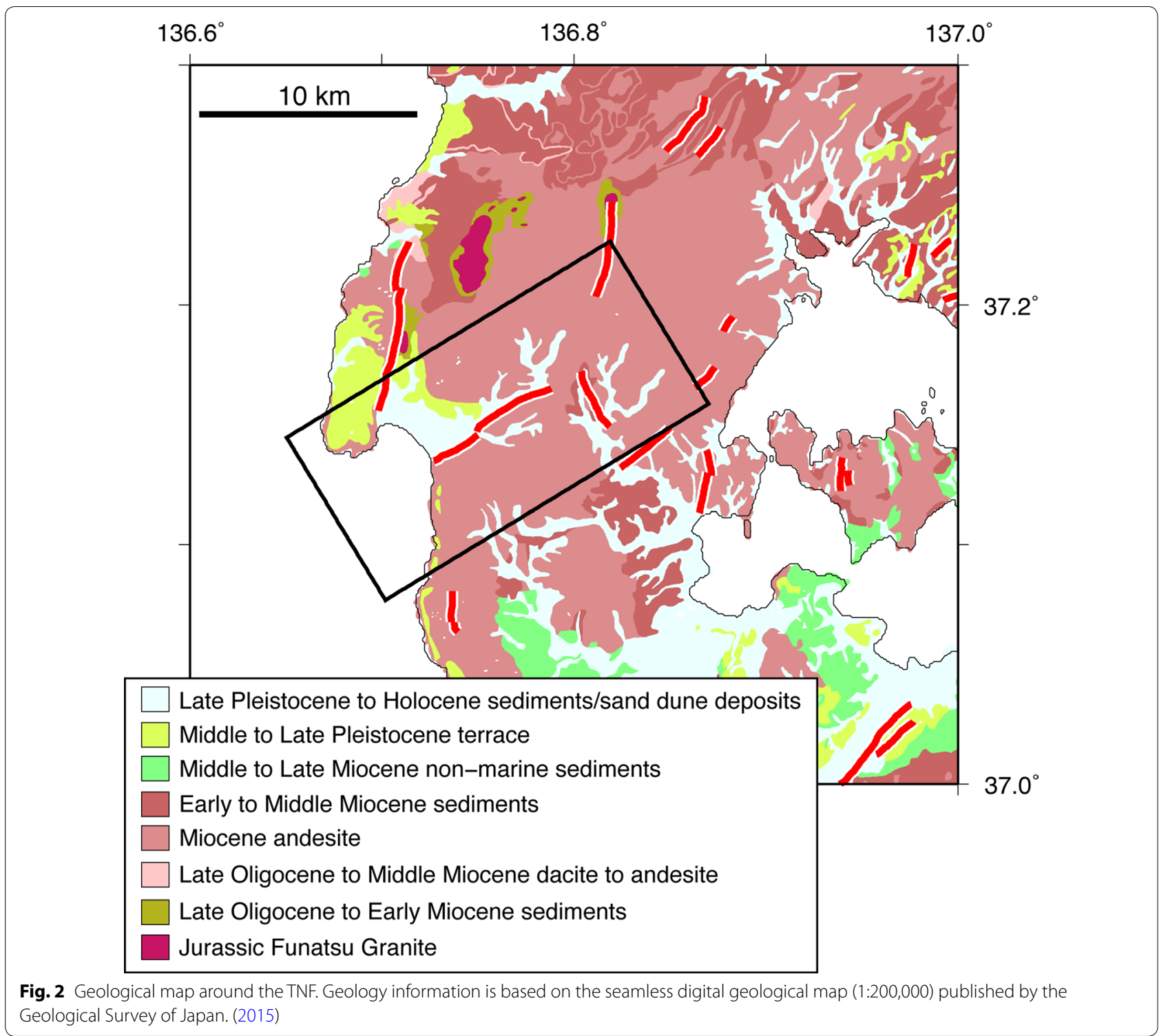

This study conducted a dense gravity survey and created a detailed gravity anomaly map around the TNF. We elucidate features of gravity anomalies and indices derived from the gravity gradient tensor around the TNF and discuss the faulting type, the continuity and size, and the dip angle of the TNF.

\section{Data and method}

\section{Gravity measurement, compilation, and corrections}

Gravity data used for this study consist mainly of two datasets. The first comprises data measured on land; the second includes data of the seafloor (Fig. 1). We conducted a gravity survey on land, around TNF using a Scintrex CG-3M gravimeter from February 26 through
September 11 in 2018 and obtained 279 gravity data (Fig. 1). For analysis of the two-dimensional density structure, we set a profile across the TNF and conducted a gravity survey with an interval of $25-50 \mathrm{~m}$ and to a maximum $173 \mathrm{~m}$ on the profile (Fig. 1). The positions of gravity measurement points were obtained from Global Navigation Satellite System (GNSS) observations. In the case of poor location of GNSS, that is, the solution is not fix, we used a 10-m mesh digital elevation model (DEM), published by the Geospatial Information Authority of Japan, for locating. For the points on the profile, we used a total station for locating. Gravity measurement of the seafloor was conducted by Hokuriku Electric Power Company from May 20 through June 20 in 2018 (Ishida 
et al. 2018). They used a Scintrex INO ocean bottom gravity meter to obtain 275 gravity data in an approximately $40 \mathrm{~km} \times 10 \mathrm{~km}$ area west of the Noto Peninsula (Additional file 1: Figure S1). The points presented in Fig. 1 do not cover all areas for which gravity measurements were conducted on the seafloor. These gravity data from the seafloor filled a clearly apparent gap left by earlier gravity measurement data published by the Geological Survey of Japan (2013) and Murata et al. (2018) for the sea area (Fig. 1).

In addition to the data described above, we compiled gravity data reported by the Geographical Survey Institute (2006), Yamamoto et al. (2011), Honda et al. (2012), and the Geological Survey of Japan (2013). Data of the Geological Survey of Japan (2013) include data of shipboard gravity measurements described above. We applied terrain correction with the 10-m mesh DEM, and a plain trend correction, together with normal correction procedures (e.g., tide, drift, free-air, and Bouguer corrections), to the compiled gravity data. The values of the density used for the terrain and the Bouguer corrections are $2300 \mathrm{~kg} / \mathrm{m}^{3}$ because we used Bouguer anomaly data created from the shipboard gravity measurements with correction density of $2300 \mathrm{~kg} / \mathrm{m}^{3}$ (Geological Survey of Japan 2013). These values are close to the optimum correction density of $2350 \mathrm{~kg} / \mathrm{m}^{3}$ in the large area including most of the Noto Peninsula (Murata et al. 2018). Furthermore, we applied a low-pass filter with a cut-off wavelength of $3000 \mathrm{~m}$ to the Bouguer anomalies as a Bouguer anomaly map for the analysis of the gravity gradient tensor (Fig. 1).

\section{Estimation of gravity gradient tensor and related indices}

The gravity gradient tensor is defined by the partial derivatives of the gravity vector $\left(g_{x}, g_{y}, g_{z}\right)$ as

$$
\left[\begin{array}{lll}
\frac{\partial g_{x}}{\partial x} & \frac{\partial g_{x}}{\partial y} & \frac{\partial g_{x}}{\partial z} \\
\frac{\partial g_{y}}{\partial x} & \frac{\partial g_{y}}{\partial y} & \frac{\partial g_{y}}{\partial z} \\
\frac{\partial g_{z}}{\partial x} & \frac{\partial g_{z}}{\partial y} & \frac{\partial g_{z}}{\partial z}
\end{array}\right]=\left[\begin{array}{lll}
g_{x x} & g_{x y} & g_{x z} \\
g_{y x} & g_{y y} & g_{y z} \\
g_{z x} & g_{z y} & g_{z z}
\end{array}\right] \text {. }
$$

Assuming a Bouguer anomaly as $g_{z}$, as measured on the $x-y$ plane, the gravity gradient tensor is calculated using the Fourier transform of $g_{z}$ as proposed by Mickus and Hinojosa (2001). From the gravity gradient tensor, the first horizontal derivative (HD), the first vertical derivative (VD), and the normalized total horizontal derivative (TDX) (Cooper and Cowan 2006) are defined as

$$
\begin{aligned}
& \mathrm{HD}=\sqrt{g_{z x}^{2}+g_{z y}^{2}}, \\
& \mathrm{VD}=g_{z z},
\end{aligned}
$$

$$
\mathrm{TDX}=\tan ^{-1}(\mathrm{HD} /|\mathrm{VD}|)=\tan ^{-1}\left(\sqrt{g_{z x}^{2}+g_{z y}^{2}} /\left|g_{z z}\right|\right) .
$$

These indices are useful to detect a subsurface density discontinuity such as a fault structure. The strike and dip angles of a two-dimensional causative body can be estimated from the minimum and maximum eigenvectors of a gravity gradient tensor (Beiki 2013). Kusumoto (2015) demonstrated that the dip angle of a fault plane can be estimated from the maximum eigenvector. Recently, Kusumoto (2017) demonstrated from a numerical simulation that the dip of the minimum eigenvector followed the dip of a reverse fault. Using the minimum eigenvector, he estimated the dip angle of a reverse fault in central Japan: the Kurehayama fault. He emphasized the importance of the selection of the eigenvector by consideration of the faulting type: a normal fault or a reverse fault. For a reverse fault, the dip angle defined by the minimum eigenvector of a gravity gradient tensor $\left(v_{3 x}, v_{3 y}, v_{3 z}\right)$ is given as

$$
\beta_{\min }=\tan ^{-1}\left(v_{3 z} / \sqrt{v_{3 x}^{2}+v_{3 y}^{2}}\right) .
$$

The geological setting of this study area is similar to that of Kusumoto (2017). We therefore used this formulation to estimate the TNF dip angle. The dimensionality index $D_{i}$ is defined by using the eigenvalues $\lambda_{1}, \lambda_{2}, \lambda_{3}$, of a gravity gradient tensor as

$$
D_{i}=-27 I_{2}^{2} / 4 I_{1}^{3} \text {, }
$$

where $I_{1}=\lambda_{1} \lambda_{2}+\lambda_{2} \lambda_{3}+\lambda_{1} \lambda_{3}$ and $I_{2}=\lambda_{1} \lambda_{2} \lambda_{3}$ (Pedersen and Rasmussen 1990). $D_{i}$ indicates whether the subsurface structure is approximately two-dimensional $\left(D_{i}\right.$ approaches 0$)$ or three-dimensional $\left(D_{i}\right.$ approaches 1).

\section{Two-dimensional Talwani's method}

In addition to the gravity gradient tensor analysis, we applied the two-dimensional (2D) Talwani's method (Talwani et al. 1959) to verify the subsurface density structure of the TNF, especially for the dip angle, obtained through gravity gradient tensor analysis. The Bouguer anomaly data for the 2D density structure analysis were produced from the gravity data measured on the profile traversing the TNF (Fig. 1). We set a line across the TNF as shown in Fig. 1 and projected the observed Bouguer anomalies on the profile onto the line. After the projection, we smoothed and resampled the data with an interval of $100 \mathrm{~m}$ using the trend 1D command of Generic Mapping Tools (Wessel and Smith 1998) (Fig. 3a).

We assume for these analyses that the density structure mainly comprises two layers: andesite distributed widely 


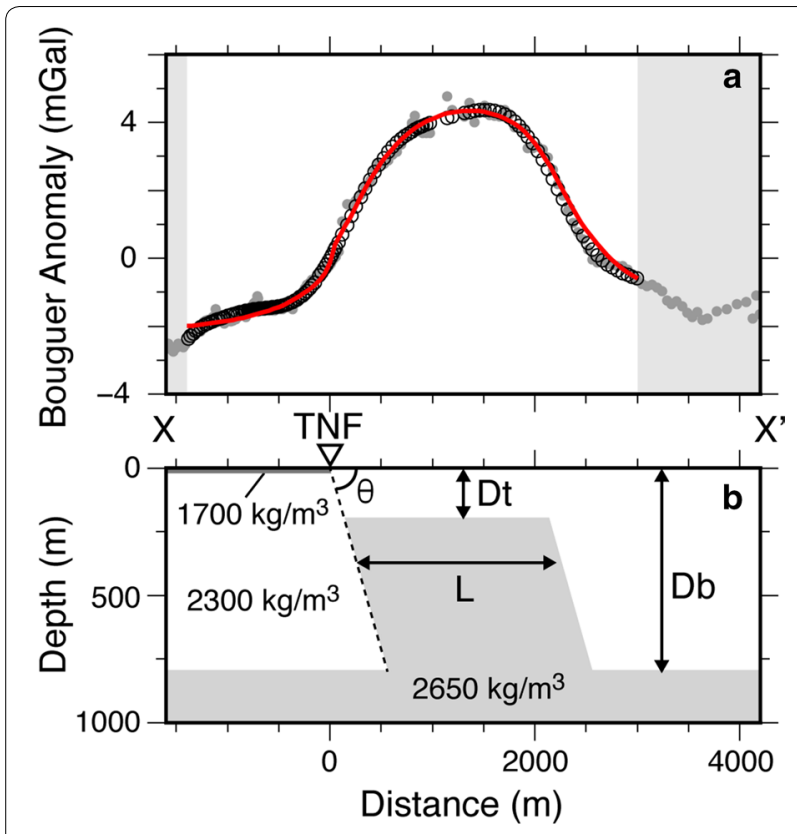

Fig. 3 a Comparison of observed Bouguer anomalies projected on the line $X-X^{\prime}$ across the TNF (gray circles), the smoothed and resampled ones (open circles), and those calculated from the optimum density structure using the 2D Talwani's method (red line). Data in the gray areas are not used for the calculation. $\mathbf{b}$ Schematic view of the model parameters of the $2 \mathrm{D}$ density structure. A triangle shows the location of the surface trace of the TNF (at distance $=0$ ). A dark gray layer near the surface represents the sediment layer with $20 \mathrm{~m}$ thickness

in and around the analyzed area, and granite as the basement rock in the Noto Peninsula. In addition, a sediment layer lies on top of the geological features in and around the analyzed area (Fig. 2). To reduce tradeoff between the model parameters, we fix several parameters as follows. The andesite density is set as $2300 \mathrm{~kg} / \mathrm{m}^{3}$. That of granite is set as $2650 \mathrm{~kg} / \mathrm{m}^{3}$. Based on the boring data (Hokuriku Geological Information Utilization Meeting 2019), the sediment layer density and thickness are set, respectively, as $1700 \mathrm{~kg} / \mathrm{m}^{3}$ and $20 \mathrm{~m}$. Furthermore, the up-heaved part of the basement is assumed to have a parallelogram shape. The model parameters of the $2 \mathrm{D}$ density structure are presented in Fig. 3b. Two boring data to the south of the analyzed area (Fig. 1) indicate that the basement depth is $1000 \mathrm{~m}$ (Sutou et al. 2004). Sutou et al. (2004) estimated the basement depth of the southern side of the analyzed area as 500-1000 m. The geological map shows that Funatsu granite, which is recognized as the basement in this region, is distributed on the ground to the north of the analyzed area (Fig. 2). Therefore, we set the maximum depth of the basement to be $1000 \mathrm{~m}$ for the following modeling. Search ranges and intervals of the model parameters are 200-1000 m and
$100 \mathrm{~m}$, respectively, for the depth of the basement in the non-upheaval part (Db), $100-800 \mathrm{~m}$ and $100 \mathrm{~m}$ for the depth of the basement in the upheaval part (Dt), $20^{\circ}-80^{\circ}$ and $5^{\circ}$ for the dip angle $(\theta)$, and 1500-2500 $\mathrm{m}$ and $100 \mathrm{~m}$ for the horizontal length of the upheaval part $(L)$. The optimum model is selected by minimizing the L2 norm between the resampled and calculated Bouguer anomalies, defined as $\sum_{i}\left|O_{i}-C_{i}\right|^{2}$, where at the $i$ th point on the line, $O_{i}$ is the resampled Bouguer anomaly on the line and $C_{i}$ is the Bouguer anomaly calculated from a model using the 2D Talwani's method. We estimate the 95\% confidence ranges of the optimum parameters based on the Chi square distribution as well.

\section{Results and discussion}

Faulting type, continuity and size, and dip of the TNF

We discuss here the faulting type, the size, and the dip angle of the TNF from the features of the Bouguer anomalies and the indices derived from the gravity gradient tensor. Around the TNF, the Bouguer anomalies are high on the southeastern side and low in the northwestern side of the TNF, indicating that the basement depth of the southeastern side is shallower than that of the northwestern side (Fig. 1). For indices derived from the gravity gradient tensor, high HD ( $>2 \mathrm{mGal} / \mathrm{km})$ and high TDX $\left(>75^{\circ}\right)$ are distributed parallel to the strike of the TNF mainly in the southeastern side of the TNF (Fig. 4). We recognize that VD is high on the southeastern side and low on the northwestern side of the TNF. This difference also indicates that the basement depth of the southeastern side is shallower than that of the northwestern side. Furthermore, the zero isoline of VD, which illustrates a subsurface geological discontinuity, lies parallel to the strike of the TNF mainly in the southeastern side. These features indicate that the TNF is a reverse fault dipping to the southeast. This fault type estimated from the indices is coincident with that based on geological and geomorphologic observations (Active Fault Research Group 1991; Imaizumi et al. 2018).

The spatial extent of high HD along the TNF is almost identical to that of the surface trace of the TNF reported by Imaizumi et al. (2018) (Fig. 4). The high TDX zone along the TNF is crossed by other high TDX zones with north-south orientation near the coast and at the northeastern extension of the TNF. The zero isoline of VD along the TNF also bends perpendicularly near the coast and at the northeastern extension of the TNF. Low $D_{i}(<0.5)$, which indicates that the subsurface structure is close to two-dimensional one, is distributed over an almost identical range of the total length of the TNF and high $D_{i}(>0.5)$, which indicates that the subsurface structure is nearly three-dimensional near both edges of the TNF. We infer from these features that the size of 

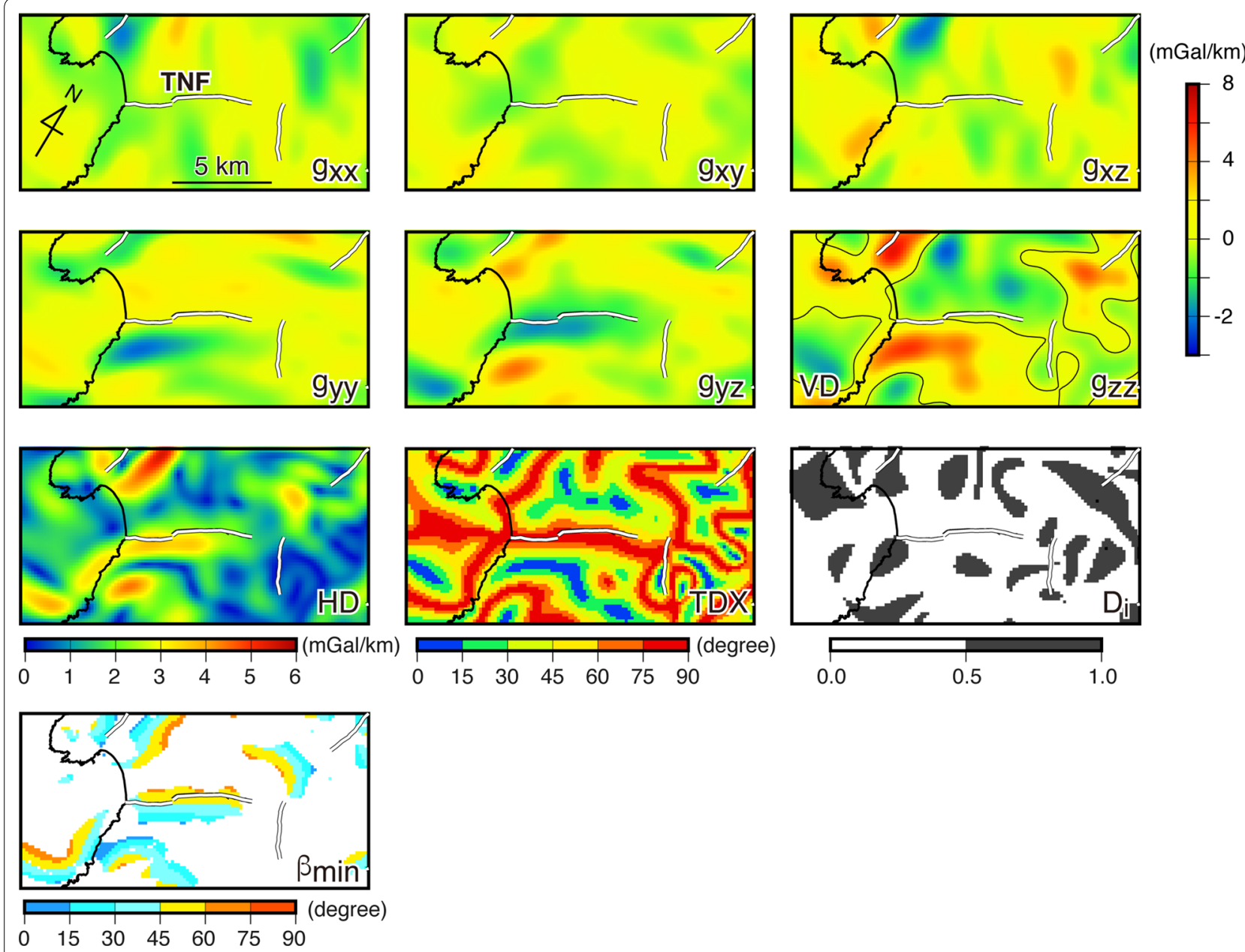

Fig. 4 Maps of the six components of gravity gradient tensor and indices (HD, VD, TDX, $\left.D_{i}, \beta_{\mathrm{min}}\right)$ calculated from gravity gradient tensor components. White lines are active faults. Black lines in the VD $\left(g_{z z}\right)$ panel represent the zero isoline of VD. White and dark gray areas, respectively, in the $D_{i}$ panel indicate that whether the subsurface structure is approximately two-dimensional or three-dimensional. $\beta_{\min }$ shows the dip angle of the subsurface structure

the subsurface fault structure of the TNF is comparable to that of the surface trace. It is also noteworthy that the TNF shows no continuous structure with surrounding active faults based on the indices calculated from the gravity gradient tensor.

To estimate a fault dip angle, Kusumoto (2016) proposed that $\beta_{\min }$ of a fault structure should be evaluated in areas with high HD and low $D_{i}$ because a two-dimensional subsurface fault structure satisfies both these conditions. Figure 4 shows the distribution of $\beta_{\min }$ in areas with $\mathrm{HD} \geq 2 \mathrm{mGal} / \mathrm{km}$ and $D_{i}<0.5$. We took the absolute value of $\beta_{\min }$ for use in the plot because we are concerned about the dip angle. From $\beta_{\min }$ along the TNF, we can estimate that the dip angle of the TNF is approximately $45^{\circ}-60^{\circ}$.

\section{Two-dimensional density structure analysis}

To assess the adequacy of the dip angle estimated from the gravity gradient tensor analysis in Subsect. "Faulting type, continuity and size, and dip of the TNF" section, this subsection presents estimation of the dip angle of the TNF using the 2D Talwani's method. For calculation, we set the value of the resampled gravity anomaly on the fault trace, at Distance $=0$ in Fig. 3a, as 0. Figure 3a compares the observed Bouguer anomalies projected onto the line across the TNF and the resampled ones to the synthetic ones calculated from the optimum subsurface density structure using the 2D Talwani's method. The optimum parameters, which provide the minimum L2 norm, and those 95\% confidence range in the parentheses of $\mathrm{Db}, \mathrm{Dt}, \theta$, and $L$ are, respectively, $800 \mathrm{~m}(600-1000 \mathrm{~m}), 200 \mathrm{~m}(100-300 \mathrm{~m}), 55^{\circ}\left(40-65^{\circ}\right)$, and $2000 \mathrm{~m}(1900-2100 \mathrm{~m})$. The calculated Bouguer 
anomalies well reproduced the resampled ones. We also recognize the tradeoff between the parameters: $L$ and $\theta$ become large and $\mathrm{Db}$ becomes small as $\mathrm{Dt}$ becomes small, and vice versa. The optimum parameters are essentially sensitive to the assumed density: those for the andesite density of $2200 \mathrm{~kg} / \mathrm{m}^{3}$ are $\mathrm{Db}$ of $800 \mathrm{~m}$, Dt of $300 \mathrm{~m}, \theta$ of $60^{\circ}$, and $L$ of $2000 \mathrm{~m}$ and those for the andesite density of $2400 \mathrm{~kg} / \mathrm{m}^{3}$ are $\mathrm{Db}$ of $900 \mathrm{~m}$, Dt of $100 \mathrm{~m}, \theta$ of $55^{\circ}$, and $L$ of $2000 \mathrm{~m}$. It is important that a high dip angle is estimated as the optimum parameter irrespective of the assumed density of the andesite.

The optimum dip angle of $55^{\circ}$ obtained using the $2 \mathrm{D}$ Talwani's method is coincident with that estimated from the gravity gradient tensor analysis. This result supports not only the estimation of the dip angle of the gravity gradient tensor analysis but also the validity of the estimation of the dip angle of a reverse fault from the minimum eigenvector proposed by Kusumoto (2017). This result also shows that the gravity gradient tensor analysis is as useful as the 2D Talwani's method for estimating the dip angle of a fault structure and has an advantage of estimating widely the distribution of the dip angle.

\section{Implications for TNF formation processes}

The TNF dip angle estimated as explained in the preceding two subsections is high for a reverse fault. We discuss here what this high dip angle means. The 2007 Noto Hanto earthquake ( $M_{\mathrm{JMA}}$ 6.9) occurred on the Noto Peninsula about $15 \mathrm{~km}$ north of the TNF (Fig. 1). The source mechanism is a reverse fault with right lateral slip. Seismic and geodetic analyses indicate the dip angle of the fault plane as $60^{\circ}$ (e.g., Hiramatsu et al. 2008; Kato et al. 2008; Sakai et al. 2008). Consequently, the estimated dip angle of the TNF, as a reverse fault with high dip angle, is coincident with that of the 2007 Noto Hanto earthquake. Furthermore, the strike of the TNF, with a northeast to southwest orientation, is the same as that of the 2007 Noto Hanto earthquake. A reverse fault with a high dip angle has been formed by inversion tectonics (e.g., Nakamura 1992). Previous reports have described that some active faults in sea areas around the Noto Peninsula, including the source fault of the 2007 Noto Hanto earthquake, have experienced inversion tectonics (Yoshikawa et al. 2002; Katagawa et al. 2005; Okamura 2007). In other words, those faults have been formed as normal faults accompanying the opening of the Sea of Japan. They have reactivated as reverse faults by crustal shortening initiated from the late Miocene. Inversion tectonics of this kind were inferred for the 2004 mid-Niigata Prefecture earthquake, which occurred in a similar tectonic setting in coastal areas of the Sea of Japan (Kato et al. 2006). In this case also, we infer that the TNF might have experienced the inversion tectonics.

\section{Conclusions}

We have conducted gravity anomaly and gravity gradient tensor analyses around the Togi-gawa Nangan fault (TNF) of the Noto Peninsula, central Japan. Indices such as the first horizontal and vertical derivatives derived from the gravity gradient tensor, as well as Bouguer anomalies, indicate that the TNF is a reverse fault dipping to southeast. We illustrate the subsurface fault structure as an area with a high first horizontal derivative and a low dimensionality index along the TNF. The spatial extent of the area is comparable to the total length of the surface trace of the TNF. We observe no continuity between the TNF and other surrounding active faults. The minimum eigenvectors of the gravity gradient tensor indicate the dip angle of the TNF as $45^{\circ}-60^{\circ}$. Modeling using the 2D Talwani's method supports this dip angle. Comparison of the dip angle of the TNF to those of the source fault of recent large earthquakes in/around the Noto Peninsula suggests that the TNF has experienced inversion tectonics.

\section{Supplementary information}

Supplementary information accompanies this paper at https://doi. org/10.1186/s40623-019-1088-5.

Additional file 1: Figure S1. Distribution of the gravity measurements points in the sea area west off the Noto Peninsula. Red and gray circles, respectively, are those on the seafloor reported by Ishida et al. (2018) and those reported by Geological Survey of Japan (2013).

\section{Abbreviations}

TNF: Togi-gawa Nangan fault; HD: first horizontal derivative; VD: first vertical derivative; GNSS: Global Navigation Satellite System; DEM: digital elevation model; TDX: normalized total horizontal derivative.

\section{Acknowledgements}

We used gravity data reported by Yamamoto et al. (2011), Geological Survey of Japan (2013), Geographical Survey Institute (2006), and Ishida et al. (2018). We also used the DEM with a $10 \mathrm{~m}$ mesh provided by Geospatial Information Authority of Japan and boring data provided by Hokuriku Geological Information Utilization Meeting. All figures were created using Generic Mapping Tools software (Wessel and Smith 1998). Constructive comments from anonymous reviewers are useful to improve the manuscript.

\section{Authors' contributions}

$\mathrm{YH}$ and $\mathrm{MH}$ designed this study. $\mathrm{AS}, \mathrm{SI}, \mathrm{WK}$, and $\mathrm{MH}$ took gravity measurements. YH and AS conducted analyses. YH drafted the manuscript. All authors read and approved the final manuscript.

\section{Funding}

The analyses conducted for this study were partly supported by JSPS KAKENHI Grant Number 17 K05629.

\section{Availability of data and materials}

Datasets of gravity anomalies used for this study are available from the corresponding author on reasonable request. 


\section{Competing interests}

The authors declare that they have no competing interests.

\section{Author details}

1 School of Geosciences and Civil Engineering, College of Science and Engineering, Kanazawa University, Kakuma, Kanazawa, Ishikawa 920-1192, Japan. ${ }^{2}$ Hokuriku Electric Power Company, Ushijima 15-1, Toyama, Toyama 930-8686, Japan

Received: 1 August 2019 Accepted: 10 October 2019

Published online: 22 October 2019

\section{References}

Active Fault Research Group (1991) Active Faults in Japan: sheet map and inventories. University of Tokyo Press, Tokyo (in Japanese)

Beiki M (2013) TSVD analysis of Euler deconvolution to improve estimating magnetic source parameters: an example from the Åsele area, Sweden. J Appl Geophys 90:82-91

Beiki M, Pedersen LB (2010) Eigenvector analysis of gravity gradient tensor to locate geologic bodies. Geophysics 75(6):137-|49

Cooper GRJ, Cowan DR (2006) Enhancing potential field data using filters based on the local phase. Comput Geosci 32:1585-1591

Geographical Survey Institute (2006) Search of gravity data. http://vldb.gsi. go.jp/sokuchi/gravity/grv_search/gravity.pl Accessed December 26, 2015. (in Japanese)

Geological Survey of Japan, AIST (Eds.) (2013) Gravity database of Japan DVD Edition, Digital Geoscience Map P-2. Geological Survey of Japan, AIST, Tsukuba

Geological Survey of Japan, AIST (ed.) (2015) Seamless digital geological map of Japan 1: 200,000. May 29, 2015 version. Geological Survey of Japan, AIST, Tsukuba

Hiramatsu Y, Moriya K, Kamiya T, Kato M, Nishimura T (2008) Fault model of the 2007 Noto Hanto earthquake estimated from coseismic deformation obtained by the distribution of littoral organisms and GPS: implication for neotectonics in the northwestern Noto Peninsula. Earth Planets Space 60:903-913. https://doi.org/10.1186/BF03352846

Hokuriku Geological Information Utilization Meeting (2019) Hokuriku Geological Information System. https://www.hokuriku-jiban.info. Accessed 1 July 2019 (in Japanese)

Honda R, Sawada A, Furuse N, Kudo T, Tanaka T, Hiramatsu Y (2012) Release of gravity database of the Kanazawa University. J Geod Soc Jpn 58(4):153160 (in Japanese with English abstract)

Imaizumi T, Miyauchi T, Tsutsumi H, Nakata T (2018) Digital active fault map of Japan. University of Tokyo Press, Tokyo (in Japanese)

Ishida S, Miyamoto S, Yoshida S (2018) The outline of gravity measurement on seafloor in the sea area in front of the Shika nuclear power plant. Electr Power Civil Eng 398:110-114 (in Japanese)

Kaseno Y (1993) Geology of Ishikawa-ken, Japan (with Geological Maps). pp 321, Ishikawa Pref. and Hokuriku Geology Institute (in Japanese)

Katagawa H, Hamada M, Yoshida S, Kadosawa H, Mitsuhashi A, Kono Y, Kinugasa Y (2005) Geological development of the west sea area of the Noto Peninsula district in the Neogene Tertiary to Quaternary, central Japan. J Geogr 114:791-810 (in Japanese with English abstract)

Kato A, Sakai S, Hirata N, Kurashimo E, lidaka T, Iwasaki T, Kanazawa T (2006) Imaging the seismic structure and stress field in the source region of the 2004 mid-Niigata prefecture earthquake: structural zones of weakness and seismogenic stress concentration by ductile flow. J Geophys Res 111:B08308. https://doi.org/10.1029/2005JB004016

Kato A, Sakai S, lidaka T, Iwasaki T, Kurashimo E, Igarashi T, Hirata N, Kanazawa T, Group for the aftershock observation of the 2007 Noto Hanto Earthquake
(2008) Three-dimensional velocity structure in the source region of the Noto Hanto Earthquake in 2007 imaged by a dense seismic observation. Earth Planets Space 60:105-110. https://doi.org/10.1186/BF03352769

Kusumoto S (2015) Estimation of dip angle of fault or structural boundary by eigenvectors of gravity gradient tensors. Butsuri-Tansa 68(4):277-287 (in Japanese with English abstract)

Kusumoto S (2016) Dip distribution of Oita-Kumamoto tectonic line located in central Kyushu, Japan, estimated by eigenvectors of gravity gradient tensor. Earth Planets Space 68:153. https://doi.org/10.1186/s4062 3-016-0529-7

Kusumoto S (2017) Eigenvector of gravity gradient tensor for estimating fault dips considering fault type. Prog Earth Planet Sci 4:15. https://doi. org/10.1186/s40645-017-0130-0

Matsumoto N, Hiramatsu Y, Sawada A (2016) Continuity, segmentation and faulting type of active fault zones of the 2016 Kumamoto earthquake inferred from analyses of a gravity gradient tensor. Earth Planets Space 68:167. https://doi.org/10.1186/s0623-016-0541-y

Mickus KL, Hinojosa JH (2001) The complete gravity gradient tensor derived from the vertical component of gravity: a Fourier transform technique. J Appl Geophys 46:159-174

Murata Y, Miyakawa A, Komazawa M, Nawa K, Okuma S, Joshima M, Nishimura K, Kishimoto K, Miyazaki T, Shichi R, Honda R, Sawada A (2018) Gravity map of Kanazawa District (Bouguer Anomalies). Gravity Map Series 33, Geological Survey of Japan, AIST

Nakamura K (1992) Inversion tectonics and its structural expression. J Tectonic Res Group Jpn 38:3-45 (in Japanese with English abstract)

Okamura Y (2007) Tectonic evolution and active tectonics of the Noto Peninsula (Hanto) and its surrounding area. Ann Rep Act Fault Paleoearthq Res 7:197-207 (in Japanese with English abstract)

Pedersen LB, Rasmussen TM (1990) The gradient tensor of potential field anomalies: some implications on data collection and data processing of maps. Geophysics 55(12):1558-1566

Sakai S, Kato A, lidaka T, Iwasaki T, Kurashimo E, Igarashi T, Hirata N, Kanazawa T, the group for the joint aftershock observation of the 2007 Noto Hanto Earthquake (2008) Highly resolved distribution of aftershocks of the 2007 Noto Hanto Earthquake by a dense seismic observation. Earth Planets Space 60:83-88. https://doi.org/10.1186/BF03352765

Sutou H, Kitaguchi Y, Yamamoto K, Kono Y (2004) Gravity anomalies and basement structures in southern part of the Noto Peninsula, Japan. J Seismol Soc Jpn 56:363-377

Talwani M, Worzel JL, Landisman M (1959) Rapid gravity computations for two-dimensional bodies with application to the Mendocino Submarine Fracture Zone. J Geophys Res 64:49-59

Wada S, Sawada A, Hiramatsu Y, Matsumoto N, Okada S, Tanaka T, Honda R (2017) Continuity of subsurface fault structure revealed by gravity anomaly: the eastern boundary fault zone of the Niigata plain, central Japan. Earth Planets Space 69:15. https://doi.org/10.1186/s40623-017-0602-x

Wessel P, Smith WHF (1998) New, improved version of the Generic Mapping Tools released. EOS Trans Am Geophys Union 79(47):579

Yamamoto A, Shichi R, Kudo T (2011) Gravity database of Japan (CD-ROM). Special Publication No. 1. The Earth Watch Safety Net Research Center, Chubu University, Nagoya

Yoshikawa T, Kano K, Yanagisawa Y, Komazawa M, Joshima M, Kikawa E (2002) Geology of the Suzumisaki, Noto-iida and Hōryūzan district. Quadrangle Series, 1:50,000, Geological Survey of Japan, AIST, p 76. (in Japanese with English abstract)

\section{Publisher's Note}

Springer Nature remains neutral with regard to jurisdictional claims in published maps and institutional affiliations. 